\title{
On the Genetics of Military Operations: A Powerful Metaphor
}

\author{
JOBBÁGY Zoltán ${ }^{1}$
}

\begin{abstract}
Military operations are complex adaptive systems in which the means applied must be regarded as important as the ends sought. Complex adaptive systems work in an everything-affects-everything mode with various levels of interrelatedness. Con- ceptualizing military operations as a complex adaptive system allows biological evolution to be used as point of departure. Thus military operations are seen as a process that rests on adaptation and mutation in which the challenge is to offset changing conditions coming both from the environment and interaction with the enemy. The effects landscape as proposed metaphor makes clear that evolution by natural selection and the conduct of war are intimately related. Both reflect con-flict, survival, and conquest in a very similar and fundamental way. The proposed metaphor helps think about military operations differently by also offering some advantages.
\end{abstract}

Modern military operations are non-linear and context-dependent. They are complex adap- tive systems in which the whole is always more than the sum of the parts. [1] In such a system comprehending all relationships between causes and effects exceeds anything predictable. The same phenomenon understood in a given context can often become obscure in another. Even if laws are applicable at one level, they might become entirely upset at another. Any attempt to address causality must shift from end-states towards transitional states in which the means applied must be regarded as important as the ends sought. Whatever the effects achieved they reflect combinations that come as much from trialand-error mechanisms as from careful processes of optimizing. [2]

\section{Military Operations and Scientific Thinking}

The theory of complex adaptive systems indicates that assumptions on clear causality in mil- itary operations display major conceptual and methodological weaknesses, and are danger- ously disconnected from war's true nature. Although the search for causal relationships has always been fashionable, a causal focus often lacks both substance and meaningful content. It is empty, occasionally harmful and never takes war's proverbial friction fully into account. [3] Focusing on causality in military operations reflects an equilibrium-oriented thinking. It assumes that it is possible to predict endstates based on analytical rationality. However, mil- itary operations display dynamic equilibrium or far from equilibrium conditions. Causality oriented thinking addresses military operations in scientific terms, but analytical skills based on direct causality are valid only within a limited range. Beyond that they are not able to de-

1 National University of Public Service, Budapest, Hungary, The Faculty of Military Sciences and Officer Training, Jobbagy.Zoltan@uni-nke.hu 
liver satisfactory explanations. [4] The causal focus of common science emphasises actions on the environment by promising better ways to organise and exploit the world. However, scientific homogeneity exploiting causal relationships cannot get entirely rid of instability. Even abstract mathematical precision and rigour are approximate descriptions of imprecise processes displaying multi-layered problems. [5]

Common science and its supporting paradigms ignore most human attributes that consti- tute a very important part of military operations. Clausewitz was not short in emphasising that apprehensions, sensations, perceptions, impulses, and emotions are essential ingredients of war. The theory of complex adaptive systems demands thinking holistically. It is important to consider opposites, as one side (chaos) cannot be right at the expense of the other (stasis): military operations often allow for polarities to manage rather than problems to solve. [6] To comprehend the dynamics of military operations an approach is needed that is less rigid and more flexible, less artificial and more natural, less mechanistic and more organic; one that emphasises actions in the environment. [7]

\section{Domains of Military Operations}

Military operations consist of so many factors that it is impossible to include all applicable forces and the complexity of their interactions. Clausewitz stated that war is an activity in which both the enemy's physical and psychic forces have to be destroyed. Whereas the de- struction of the former can be seen as the means of war, the latter is its objective. Clausewitz advocated that efforts had to be aimed at the enemy's power of resistance, which was "the total means at his disposal and the strength of his will". Thus war can end only if the ene- my's will is broken through a "gradual exhaustion of his physical and moral resistance." [8] A complex adaptive system works in an everything-affectseverything mode with various levels of interrelatedness. According to Clausewitz it is possible to discern two different, but interrelated domains of war such as the material and the non-material. These domains dis- play military operations as an "extreme trial of moral and physical strength and stamina" in which the actions of the belligerents aim at the "gradual exhaustion of the [enemy's] physical and moral resistance." [9]

The material domain represents categories such as physical strengths and stamina. It de- scribes the space the military tries to influence through combat and manoeuvre. Consequent- ly, the material domain deals with tangible items the enemy usually needs to wage war. It includes assets such as physical platforms and communications networks. This domain is the traditional basis for measuring combat power, which has to be rendered inoperable. The material domain can also be described as reality proper. Attempts to achieve effects in this domain must aim at physical ability and as a consequence serve the purpose of changing functions. The non-material domain on the other hand, is characterised by psychological fac- tors such as moral strength and stamina. It represents the mind and attributes that generally influence the will in the form of perception, awareness, understanding, belief, and values. Effects in this domain stand for influencing intangibles the enemy needs to wage war. Con- sequently, effects in this domain serve to change behaviour. [10]

When compared to the material domain, the non-material domain is at first appearance non-existent. However, by holding things together it permeates all human endeavours. It is the medium in which act and will merge, and points towards the ability and movement to act. 
Despite the difference regarding the two domains there is a strong correlation between them as physical and psychological factors form an organic whole. [11] Clausewitz regarded two domains standing for moral and physical elements both inseparable and interacting. The only difference he saw between the two is that the moral element is the "most fluid element of all". [12] Clausewitz also emphasised that war is "a trial of moral and physical forces through the medium of the latter" in which "psychological forces exert a decisive influence on the elements involved". [13] Whereas Clausewitz regarded the physical as the "wooden hilt," the psychological was for him "the real weapon, the finely honed blade." [14]

\section{Holistic Approach by Using Metaphor}

A holistic approach to military operations means less certainty, and challenges the human preference for clear boundaries with distinct and potentially solvable problems. Simply put, focusing on certainty is analogous with a life spent in the box. It excludes the different and includes the similar without questioning the latter. An exclusive focus on certainty means that nothing is tolerated beyond its contours. In contrast, military operations are full of evidence that certainty and uncertainty always mix and are separated only by boundaries in human thinking. [15]

Complex adaptive systems are composed of waxing and waning structures that constantly emerge and change. In the course of military operations it is not difficult to detect qualitatively different occurrences composed of emergent and selforganising attributes. The result is chang- ing and evolving boundaries that depend on the level of aggregation chosen, reflect the limita- tions of human cognitive resources, and the inherent human need to reduce complexity. [16]

In a holistic approach boundaries are not there to separate but to connect. Managing boundaries stand for the fact that in complex adaptive systems coping is often possible, but control is more often not. Human actions only disturb the dynamic equilibrium of complex adaptive systems, as solving problems in a given area can cause new and unexpected

prob- lems elsewhere. Conceptualising military operations as a complex adaptive system means to appreciate it as an organic whole and not as something composed of dissected entities. The term war-fighting ecosystem as coined in some military publications very well reflects this approach. [17] A holistic description of military operations however, requires the application of metaphors in order to comprehend the complex relationship of the many constituents. [18] A metaphor is an implied comparison or a figure of speech in which a word denoting a certain object or action is used for another in order to suggest an analogy. The very strength of metaphors is that they involve both sources and targets surrounded by an aura of meanings and associations. Metaphors enlarge perceptions by producing insightful connections and

interpretations. They offer a conjunction by activating a train of associations. Metaphors place the target in a new light, which might lead to a profound re-conception. Powerful met- aphors offer more than a list of associations by emphasising some aspects whilst diminishing others. They enable the individual to see and experience new connections.

Thus metaphors are "comparisons that help give shape and form to abstractions through images that are not dependent on the weaker "like" or "as" foundations of the simile." [19]

Metaphors are figurative expressions in which a word or phrase designating one thing is used to designate another in the form of an implicit comparison. Metaphors make a quali- tative leap from a reasonable, prosaic comparison to identification or fusion of two objects 
as the resulting new entity possesses the characteristics of both. Traditionally, the military has loved metaphors and military writings are full of them acting as frames of reference for facilitating discussion and developing ideas. [20]

Metaphors can also be extremely powerful and are much more significant than normally considered. Although metaphors are usually paradoxical statements, they can be very robust. They are literally false according to abstract rationality, but true according to imaginative rationality. Metaphors form essential as-gates in the human cognitive process as they enable the understanding of one thing in terms of another. Metaphors are indicators of a network of meanings that affect the processes of perception and conception. As evolving things, they are open to novelty, even mutation. They are able to capture the underlying processes of other evolving entities surprisingly well. Metaphors can help explore an interesting possi- bility space characterised by contingency and feedback. Metaphors can also be superior to analytical models when the phenomena of interest are impossible to control or the necessary assumptions unsure. [21]

Metaphors appear to be helpful aids when dealing with a complex adaptive system such as war. Four general levels of metaphors can be differentiated:

- Transfer - level one means the transfer of a single term into another context in order to create new meaning;

- Construction - level two is the construction of analogies as part of a specific theory or a general and systematic inquiry to elucidate phenomena;

- Unification - level three stands for a unifying view often symbolised by a specific term that refers to the whole frame of understanding under a given paradigm;

- Merger - level four can be seen as the most comprehensive in which science itself is understood as an irreducible metaphor. [22]

\section{Military Operations as Effects Landscape}

Conceptualising military operations as a complex adaptive system allows biological evo-lution to be used as point of departure. The emergent and self-organising attributes of both come from non-linear processes that can be characterised as much by stasis as by chaos. Whereas the former stands for equilibrium and represents spontaneous crystallisation with a high degree of order, the latter is a randomising force that points towards a disordered state. [23]

Both in military operations and biological evolution minor changes can sometimes cause catastrophic outcomes. They contain unpredictable processes and display spontaneous order that can best be described by two interrelated attributes such as fitness and co-evolution, both standing for simultaneous adaptation and change. [24] Fitness originally described the rela- tive success of a species in relation to others in its environment. No fitness is ever fixed, but changes in response to the actions of other species with which it co-evolves. In the process of co-evolution a species tries to optimise its fitness in order to gain a relative competitive advantage. Similar to the unpredictable character of war, biological evolution happens in a constantly changing environment in which a species' suitability to the circumstances often alters in a subtle and dramatic way. [25]

Biological evolution can be depicted in the form of an imaginary landscape, called the fitness landscape. Its surface is continually evolving and changing due to the action/reaction 
cycles of the belligerent. There is no guarantee that current locations of high fitness symbol- ised by high peaks remain unchanged over time as they can alter significantly. The challenge of moving about in such a landscape is to strike an appropriate balance between exploiting locations of high fitness and constantly exploring new locations that might also have a high value. [26] The inherent relationship between the military and landscapes supports such an approach in many respects:

- Literal interpretation - understands landscape as terrain with its geographical features that have always been influential for the conduct of war and warfare;

- First level of abstraction - is embodied by the topographical map that directly refers to geography since it depicts the physical landscape in standard symbols;

- Second level of abstraction - is representation by metaphor and indicates political, economic, and cultural landscapes that have no physical basis;

- Third level of abstraction - allows understanding of landscapes as tools for analysing and modelling complex problems. [27]

The proposed metaphor is on the second level of abstraction as it indicates an effects landscape that has no physical basis. The various effects achieved in military operations al- lows for this notion in which peaks stand for effects. Also effects landscapes show a number of regular properties and structures. In most cases heights of different peaks are correlated in such a way that peaks differing slightly are near each other. As the environment and the enemy change, the value attributable to any given effect will also change. Consequently, the heights of the peaks in the landscape move constantly up and down over time indicating that one effect regarded as valuable today might probably be of little help tomorrow. [28]

By better understanding the underlying properties of such an imaginary landscape it be- comes possible to think of military operations as a search process to find high peaks. Thus similar to biological evolution of species there is also a path or trajectory representing the evolution of military operations over time. An effect (E) can be seen as the function $(f)$ of an action (a) on an object (o) and depicted in the form of an equation

$$
E=f(a, o)
$$

The first part of the equation refers to actions. Well-known terms such as delay, disrupt, destroy, demoralize, deter, disrupt, degrade, decapitate, divert, dislocate, deny, deceive and defend can describe actions needed to achieve effects. [29] However, for the effects land- scape a simplification is needed. Thus an action is limited to two alternative states such as action taken standing for 1 or action not taken standing for 0 . The second part of the equation refers to object and is equivalent to the number of genes $\mathrm{N}$. In military operations, similar to living organisms the number of objects that must be considered is normally very large. An organism such as the eukaryote ${ }^{2}$ has $20000-100000$ structural genes and a variety of other control points. In order to interdict enemy ground units the Air Campaign during Operation Iraqi Freedom identified and struck approximately 19900 objects called aim points. [30]

This way it becomes possible to conceptualise effects in terms of genotypes, which in the case of military operations, is defined as the specific makeup of an effect that refers to cer- tain composition of objects. For this reason an object is understood as the focus of an action that sets the boundaries between phenomena. [31] Each effect has genes represented by bits

2 An organism with cells containing nucleus and other structures enclosed within membranes (valódi sejtmaggal rendelkezö élölény, akinél a mag anyagát a citoplazmától maghártya választja el). 
composed of binary numbers. Pairing objects with actions means that an object can either be taken into consideration in the form of action taken or left out in the form of action not taken. Consequently, the effect-genotype represents a given combination of effects and takes the simple form of a binary string with $2^{\mathrm{N}}$ possibilities. [32]

In the case of ten objects $(\mathrm{N}=10)$ and the two sorts of actions the effect-genotypes can have $2^{10}$ or 1024 various possible states ranging from 0000000000 to 1111111111 . These pos- sibilities can be depicted in the form of a landscape that contains various peaks representing the different values of the effect-genotypes. The value of any combination can be defined as the average of the contribution of the individual objects, each in its own context and the K other objects in the form of functional couplings or epistatic interactions. [33] Thus the effects landscape is defined by effectgenotypes consisting of a given number $(\mathrm{N})$ of objects (o) with two possible states at each object (oi) and can be expressed as follows

$$
F(o)=\frac{1}{n}
$$

Whereas for $\mathrm{K}=0$ each object is independent of all other objects, for $\mathrm{K}=\mathrm{N}-1$ each object depends upon itself and all other objects. Thus each object's fitness contribution depends on the choice between the two different binary states at each of the K other objects that impinge upon it. [34]

\section{Consideration and Discussion}

According to the effects landscape effects are highly complex phenomena. There is no single dimension along which it becomes possible to search and find combinations that possess good or high value. Hence predefining desired effects often do not make sense. Military operations represent a high-dimensional search process with the aim to find an optimum combination of effects. The goal is to occupy high spots on the landscape in which a given combination of effects influences battlefield performance. [35]

However, also some limitations must be acknowledged. Despite the mathematical foun- dation the effects landscape is understood in heuristic terms and the search process is not quantified more precisely. Consequently, it might not always be possible to find a search process that guarantees a good optimum, and often sub-optimal solutions must be accepted. Whereas in theory the search process is driven by an algorithm that always chooses the fittest option, it is not always possible to do that in reality. Military operations represent real-life problems that are NP complete and intractable to analytical solutions in the form of algo- rithms. [36]

A further limitation is due to the fact that cultural imprints and past experience always distort perception. Reality is not directly comprehensible and the effects landscape represents a specific mapping of reality. Identity can limit the search process by excluding certain areas that may contain good peaks, but cannot be explored or climbed. Due to these blinders, the effects landscape is always a compressed and distorted form of reality that puts limitation on the search potential. A further reason why the search process is suboptimal comes from the fact that it is not the peaks sought, but the landscape's ruggedness that determines the suc- cess of any given search. The effects landscape exists only as a representation, which means that the search process is typically constrained and appears mostly in the form of a biased 
walk. The effects landscape has no objective reality separable from the autonomous agents inhibiting it. Although this sort of bias sometimes eases the search process, it always limits the search potential. Thus any problem decomposition in the form of an effects landscape only coincides with the reality as it "may or may not correspond to the 'true' decomposition structure." [37]

An utterly false representation can induce additional and lasting interactions, which in- fluence the way alternatives are generated and evaluated. Consequently, effects landscapes refer to unique and private mappings of the actors involved. [38] This however, indicates that there will never be perfect battle-space knowledge or transparent battlefield available, only approximations with a certain error value. Due to such less-than-perfect descriptions generating wrong predictions, as time passes the desired peaks on the landscape might differ from the expected peaks, which again might differ from the actual peaks found. Thus very good strategies might often become hidden for long periods of time, but can also emerge occasionally. [39]

Whereas military operations exist in a high-dimensional space, the effects landscape can only provide a certain statistical characterizations of the space of possibilities. Thus the search space is explored in one particular direction, which always implies biased character- isation of the landscape. The way effects are constructed also does not provide clear and at- tainable information on the genotype/phenotype mapping. The way effects are generated and perceived can differ significantly. Despite its power to deliver helpful and valid statistical in- sights regarding the possibility space, the predictive power of the effects landscape is limited. In other words the effect-genotype has more to do with landscape statistics than landscape reality. It allows for analysing the search space only along a single fitness function and if the problem is multi-objective it cannot provide for further and broader generalizations. Despite all its utility, even the effects landscape is unable to capture the true nature of emergence with all its self-organizing attributes. [40]

The metaphor makes clear that any combination of effects reflects a distribution of po- tential outcomes rather than a unique outcome. Moreover, distributions overlap so that ap- proaches attempting to optimise make more sense than those attempting to maximise. Thus success and victory in military operations can be seen as a realised positive outcome rather than a maximum one. The greater the uncertainty the greater the possibility, that victory is a combination of relative superiority and fortuitous circumstances. Chance in the form of trial-and-error limits the selection of any meaningful criteria for achieving maximum ef- fects. In military operations there is no guarantee that a particular outcome in the form of desired effects is really the best one. Once chance forces the selection of a particular path and it often locks in regardless of the quality of other possibilities. Consequently, there are many possible solutions to the same problem and sometimes small, fortuitous, and trivial events determine the one event that becomes dominant. [41]

\section{Darwin, Clausewitz, and Boyd}

Darwin recognised in his book On the Origins of Species that genetic usurpation and endemic warfare share similarities as both are important forces in evolution and human history. In chapter three he drew an analogy between war, battle and natural selection and saw evolution as a "[b]attle within battle [that] must ever be recurring with varying success." This analogy 
made him conclude that "from the war of nature, from famine and death, the most exalted object which we are capable of conceiving, namely, the production of the higher animals, directly follows." Thus evolution was for him a "great and complex battle of life", which together with the Law of Battle for survival formed a recurrent pattern also in his second epic work The Decent of Man. [42]

In the framework of the proposed metaphor war is conceptualised as a complex adaptive system in which military operations represent a search process with the aim to find an appro- priate combination of effects. Effects form a large pool of possibilities and the combination of effects achieved decides over victory and defeat. As the actions of the belligerents develop, high value effects can become obsolete and effects with originally low significance can turn increasingly powerful. As the military operations shuffle back and forth between orderly and chaotic states they validate the Clausewitzian observation that every "action in war is not continuous, but spasmodic. Violent clashes are interrupted by periods of observation, during which both sides are on the defensive." [43]

He defined this attribute in the Dynamic Law in War. Clausewitz stated that in military operations periods of inaction and response change with periods of action as "periods of ac- tive warfare [would] always be interspersed with greater or smaller periods of rest". [44] The period of rest meant for him stability and equilibrium including phenomena such as physical and psychological forces, circumstances and motives. Although this continuous cycle defined war fully, Clausewitz emphasised that the "state of crisis is the real war; the equilibrium is nothing, but its reflex." [45]

The metaphor makes clear that soldiers might share similar problems with ecologists as both try to find a function that matches the crude reality of life. Boyd also advocated that evolution by natural selection and the conduct of war are intimately related. Both reflect con- flict, survival, and conquest in a very similar and fundamental way. Stability and chaos mark the two end-poles of war in which the degree of non-linearity defines both the quantity and quality of the outcome. By finding small areas of order sometimes it is possible to achieve equilibrium, but occasionally no equilibrium can be reached at all. When one understands military operations as a process that includes a trial-and-error mechanism, insights coming from evolutionary biology are very helpful as even a modest pool of effects can show an enormous amount of possible combinations. Clausewitz also pointed out that "the vast, the almost infinite distance ... between cause and its effect, and the countless ways in which these elements can be combined" demand things to be seen in a comprehensive, hence holis- tic fashion. [46]

\section{Conclusion}

When biologist Sewell Wright wanted to understand the properties of gene mutation he concluded that under biparental reproduction even a limited number of mutations can re- sult in an almost infinite field of variants. In order to handle this problem he introduced the idea of fitness landscape, which is a less rigorous and strict theory, but a more picturesque metaphor. [47]

In a similar fashion the effects landscape is a powerful aid to conceptualize war in a novel way. Military operations are seen as a process that rests on adaptation and mutation in which the challenge is to offset changing conditions coming both from the environment and inter- 
action with the enemy. Conceptualizing military operations this way also has the advantage that the emerging search process can be defined by a given network of effects and not exclu- sively by desired effects. Regardless of the approach and methodology chosen it will never be possible to explore the vast space of possibilities. However, the effects landscape can help understand the complexity of military operations. It can frame it as a complex optimization problem that includes approximations and estimations regarding optimal values. The effects landscape can also give the chance to assess the benefits of further optimization or define termination criteria. [48]

The idea of the effects landscape resembles clear similarities with the idea of network- centric warfare/network enabled operations found in military writings that are characterised by the following factors:

- the re-focus from the sum of individual platforms to the network of possibilities they provide for, and the gains that can be exploited;

- the re-focus from mostly isolated and homogenous actors to the various interdependencies smaller and more specified players stand for;

- the re-focus from strategy development in traditional terms to issues such as adapta- tion, learning and coping under continuously changing conditions. [49]

Some critics question the meaningfulness of fitness as a unit of measure and regard the theory a crude metaphor. However, even they cannot deny that the idea is a fascinating ap- proach towards visualising real-world problems by means of statistical features. In fact, even critics acknowledge that despite objections, problems and limitations, a discussion of biolog- ical evolution based on the idea of fitness can be helpful. Fitness can reveal insightful guide- lines that may be generalizable to more intricate relations of evolutionary mechanisms. [50] In sum, the effects landscape as metaphor helps one think about military operations different- ly by offering the following advantages as it:

- helps conceptualise military operations as an emergent and self-organising process;

- forces us to differentiate better between two basic aspects of adaptation such as effi- ciency and effectiveness;

- gives impetus for a different and more sophisticated understanding of course of action development in a constantly changing and dynamic environment;

- contributes to a meaningful discussion regarding issues such as command and control, and military effectiveness.

Conceptualising military operations as a complex adaptive system indicates an inher- ent difficulty when attempting to turn the insights gained into actual policies, programs and strategies. It does not offer clear and simple answers to the way armed forces should train sol- diers, write doctrines and develop leaders in the future. The $21^{\text {st }}$ century has started and as one contemporary scholar emphasised "it is time to let a hundred schools of thought bloom." [51] It is the author's hope that expanding on the analogy between war and biological evolution will be one. 


\section{References}

[1] ADAMS, T. K.: The Real Military Revolution. Parameters, Autumn (2000) 54-65.

[2] HOLLAND, J. H.: Emergence, From Chaos To Order. Oxford University Press, 1998.

[3] JOBBAGY Z. (2006): Effects-Based Operations and the Problem of Thinking Beyond: A Critical Reflection. TNO Report/Clingendael Centre for Strategic Studies, CCSS-2006-001, March 2006.

[4] BEINHOCKER, E. D.: Strategy at the Edge of Chaos. The McKinsey Quarterly, 1 (1997) 24-39.

[5] GÖDEL, K.: On Formally Undecidable Propositions of Principia Mathematica and Related Systems. Basic Books, 1962.

[6] CLAUSEWITZ, C. von: On War. Everyman's Library, 1993; Dent E. B.: Complexity Science: a Worldview Shift. Emergence, 4 (1999) 5-19.

[7] PRIGOGINE, I. / STENGERS, I.: Order Out of Chaos, Man's New Dialogue with Nature. Heinemann, 1984.

[8] Quot. in CLAUSEWITZ (1993) p. 106. [9] Quot. in CLAUSEWITZ

(1993) p. 86.

[10] ALBERTS, D. S., GARTSKA, J. J., HAYE,s R. E., SIGNORI, D. A.: Understanding Information Age Warfare. CCRP Publication Series, August 2001.

[11] HUSS, J.: Exploiting the Psychological Effects of Air Power, A Guide for the Operational Commander. Aerospace Power Journal, Winter (1999) 23-32.; McNICOLL, I.: Effects- Based Operations: Air Command and Control and the Nature of the Emerging Battle space. RUSI Journal, June (2003) 38.

[12] Quot. in CLAUSEWITZ (1993) 111. [13] Quot. in CLAUSEWITZ

(1993) 145. [14] Quot. in CLAUSEWITZ (1993) 217.

[15] MOLDEREZ, I.: Freedom and Uncertainty. Emergence, 3 (1999) 84-91.

[16] RICHARDSON, K. A., LISSACK, M. R.: On the Status of Boundaries, both Natural and Organisational: A Complex Systems Perspective. Emergence, 4 (2001) 32-49.

[17] LEVIN, S. A.: Complex Adaptive Systems: Exploring the Known, the Unknown and the Unknowable. Bulletin of the American Mathematical Society, 1 (2003) 3-19.; ALBERTS, S., GARTSKA, J. J., STEIN, F. P.: Network Centric Warfare, Developing and Leveraging. Information Superiority. CCRP Publication Series, July 2002.

[18] RICHARDSON, K. A. , LISSACK, M. R. (2001).

[19] GOVE, P. B. (1981): Webster's Third New International Dictionary of the English Language. Unabridged, Merriam-Webster Inc.; HOLLAND (1998); SAPERSTEIN, A. M.: Complexity, Chaos, and National Security Policy: Metaphors or Tools? In. Alberts, D. S., Czerwinski, T. J. (Eds.) Complexity, Global Politics, and National Security. National Defence University, June 1997, Internet, accessed 2511 2003, www.dodccrp.org/comindex.html; JABLONSKY, D.: Time's Arrow, Time's Cycle: Metaphors for a Period of Transition, Parameters, Winter (1997-98) 4-27.

[20] ILACHINSKI, A. (1996): Land Warfare and Complexity, Part I: Mathematical Background and Technical Sourcebook. Center for Naval Analyses, CIM 461; DURHAM, S. E. (1997): Chaos Theory for the Practical Military Mind. Air Command and Staff College DOI: https://doi.org/10.21236/ADA362620 
[21] BEYERCHEN, A. D.: Clausewitz, Nonlinearity, and the Importance of Imagery. In.

Alberts, Czerwinski (1997); CZERWINSKI, T. J.: Coping with the Bounds, Speculations on

Nonlinearity in Military Affairs. CCRP Publication Series, May (1998), 63-70. [22] ILACHINSKI (1996)

[23] KAUFFMAN, S. A.: Antichaos and Adaptation. Scientific American, August (1991) 64-81.

[24] KAUFMANN, S. A.(1995): At Home in the Universe, The Search for Laws of Self-Organization and Complexity. Oxford University Press; WALDROP, M. M.: Complexity, The Emerging Science at the Edge of Order and Chaos.

VIKING 1992.; KAUFMANN, S. A. (1989): Adaptation on Rugged Fitness Landscapes. In. Stein, D. L. (Ed.) Lectures in the Sciences of Complexity. Addison-Wesley Publishing Company

[25] GLENN, K. B. (2002): “Complex” Targeting: A Complexity-Based Theory of Targeting and its Application to Radical Islamic Terrorism, School of Advanced Airpower Studies, Air University Maxwell AFB; OSINGA, F. (2005): Science, Strategy and War, The Strategic Theory of John Boyd. Eburon Academic Publishers

[26] BRABAZON, T., MATTHEWS, R.: Organizational Adaptation on Rugged Landscapes. Internet, accessed 1502 2004, www.business.kingston.ac.uk/research/ intbus/paper2.pdf 3-5.

[27] DOCKERY, J. T., WOODCOCK, A. E. R. (1993): The Military Landscape, Mathematical Models of Combat. Woodhead Publishing Limited

[28] JOBBAGY Z. (2004): Literature Survey on Uncertainty, Non-linearity, Complexity and Chaos. A Ph. D. study on measuring military effects and effectiveness. TNO Report, FEL-04-B061

[29] WALKER, S. G. (1998): Targeting for Effect, Analytical Framework for Counterland Operations. School of Advanced Airpower Studies, Air University Press, Maxwell AFB; McCRABB, M. (2002): Concept of Operations For Effects-based Operations. Draft, Version 2.0, Air Force Research Laboratory, Internet, accessed 0303 2003, www.eps.gov/ EPSdata/USAF/Synopses/1142/Reference-Number-PRDA-00-06-IKFPA/Latest EBOCON OPS.doc.; WAGENHALS, L. W., LEVIS, A. H. (2003): Effects based course of action analysis in support of war games. Internet, accessed 18032003 , www.mors.org/meetings/ ebo/ebo-reads/Wagenhals_Lewis.pdf.

[30] KAUFMANN (1992); CONETTA, C. (2005): Catastrophic Interdiction: Air Power and the Collapse of the Iraqi Field Army in the 2003 War. Internet, accessed 0703 2005, www.comw.org/pda/fulltext/ 0309bm30.pdf

[31] McCRABB (2001); JOBBAGY Z. (2005): Wars, Waves and the West. Putting Effects-Based Operations into Context. TNO FEL-04-B-077; VEGO, M. N.: The Problem of Common Terminology. Joint Force Quarterly, $4^{\text {th }}$ Quarter (2006) 44-49.

[32] RINALDI, S. M. (1995): Beyond the Industrial Web, Economic Synergies and Targeting Methodologies. School of Advanced Airpower Studies, Air University Press, Maxwell AFB; KAUFMANN (1989); LEVINTHAL, D. A.: Adaptation on Rugged Landscapes. Management Science, 7 (1997) 935-950.; RAMSEY, M.(2006): GA Optimizer. Artificial Intelligence Lab, The University of Arizona, Internet, accessed 2111 2006, www.ai.bpa. arizona.edu/ mramsey/ga.html. 
[33] KAUFMANN, S. A., MACREADY, W. G.: Technological Evolution and Adaptive Organisations, Ideas from biology may find applications in economics. Complexity, 2 (1995) 26-43.; LEVINTHAL (1997); HORDIJK, W. (1994): Population Flow on Fitness Landscapes. Erasmus University Rotterdam

[34] ALTENBERG, L. (1997): NK Fitness Landscapes. In. Back T., Fogel, D., Michalewicz, Z.: The Handbook of Evolutionary Computation. Oxford University Press; GOERTZEL, B. (1996): From Complexity to Creativity Computational Models of Evolutionary, Autopoietic and Cognitive Dynamics, Internet, accessed 11122006 , www.goertzel.org/books/complex/ contents.html.

[35] RIVKIN, J. W.: Imitation of Complex Strategies. Management Science, 6 (2000) 824-844.; ILACHINSKI (1996)

[36] WEINBERGER, E.: Correlated and Uncorrelated Fitness Landscapes and How to Tell the Difference. Biological Cybernetics, 63 (1990) 325-336.; RIVKIN (2000) DOI: https://doi.org/10.1007/BF00202749

[37] BRABAZON (2004); BECKERMAN, L. P. (1999): The Non-Linear Dynamics of War. Science and Application Corporation, Internet, accessed 0407 2003, www.belisarius.com/ modern_business_strategy/beckerman/ non_linear.htm.; SMITH, E. A. (2006): Complexity, Networking and Effects-Based Approaches to Operations. CCRP Publication Series; DOSI, G., LEVINTHAL, D. A., MARENGO, L.: Bridging contested terrain: linking incentive- based and learning perspectives on organizational evolution. Industrial and Corporate Change, 2 (2003) 413-436.

[38] ROOS, J., OLIVER, D.: From Fitness Landscapes to Knowledge Landscapes. Systemic Practice and Action Research, June (1999) 279-293. DOI: https://doi.org/10.1023/A:1022451718231

[39] SAKULICH, T. J. (2001): Precision Engagement at the Strategic Level of War: Guiding Promise or Wishful Thinking. Occasional Paper No. 25, Center for Strategy and Technology, Air War College Maxwell AFB; DAVEN, C.: Effects-Based Operations: Obstacles and Opportunities. Journal of the Singapore Armed Forces, 2 (2004), Internet, accessed 3108 2004, www.mindef.gov.sg/safti/pointer/back/journals/2004/Vol30_2/3.htm; BEINHOCKER, E. D.: Robust Adaptive Strategies. MIT Sloan Management Review, Spring (1999) 95-106; RIVKIN (2000).

[40] TEO, J. T. W. (200): Pareto Multi-objective Evolution of Legged Embodied Organisms. University of New South Wales - Australian Defence Force Academy, Ph. D. Thesis

[41] ALCHIAN, A. A.: Uncertainty, Evolution, and Economic Theory. The Journal of Political Economy, 3 (1950) 211-221.; ARTHUR, B. W.: Positive Feedbacks in the Economy. Scientific American, February (1990) 92-99.

[42] CROOK, P. (1994): Darwinism, war and history, The debate over the biology of war from the 'Origin of Species' to the First World War. Cambridge University Press; Quot. in DARWIN, C. R (1859): On the Origin of Species, By Means of Natural Selection, Or the Preservation of Favoured Races in the Struggle for Life. John Murray, 73, 80, 490;

DARWIN, C. R. (1871): The Descent of Man, And Selection in Relation to Sex. John Murray DOI: https://doi.org/10.1038/ scientificamerican0290-92

[43] Quot. in CLAUSEWITZ (1993) 257. DOI: https://doi.org/10.1017/CBO9780511521348

[44] [44] Quot. in CLAUSEWITZ (1993) 260. DOI: https://doi.org/10.5962/bhl.title.24784

[45] [45] Quot. in CLAUSEWITZ (1993) 262. 
[46] GLEICK, J. (1987): Chaos, Making a New Science, Viking Penguin Inc.; BYRNE D. S (1998).: Complexity Theory and the Social Sciences, An Introduction, Routledge; ALCHIAN (1950); BOYD, J. (1986): Patterns of Conflict. Internet, accessed 2203 2005, www.d-n-i.net/boyd/pdf/poc.pdf; Quot. in CLAUSEWITZ (1993) 698.

[47] WRIGHT, S.: The Roles of Mutation, Inbreeding, Crossbreeding and Selection in Evolution. Proceedings of the Sixth International Congress of Genetics, 1932, 356-366.; JOSHI, A.: The Shifting Balance Theory of Evolution. Resonance, December (1999) 66-75.

[48] ROSÉ, H.: Complexity of Fitness Landscapes. Proceeding, International Conference on Complex Systems, Noshua, USA, 21-26. 09. 1997, Internet, accessed 1108 2005, www.first.fraunhofer.de/publikationen?prID=1167\&von =mitarbeiter

[49] CEBROWSKI, A. K., GARSTKA, J. J.: Network-Centric Warfare: Its Origins and Future. Proceedings, January (1998), Internet, accessed 1406 2006, www.usni.org/Proceedings/ Articles98/PROcebrowski.htm.

[50] GELL-MANN, M. (1994): The Quark and the Jaguar, Adventures in the Simple and the Complex. Little Brown and Company, New York; CRUZAN, M. B. (2001): Adaptive Landscapes. In. Brenner, S., Miller, J. H: Encyclopedia of Genetics. Volume 1. Academic Press; HOLLAND, J. H. (1998): Emergence, From Chaos To Order, Oxford University Press; MITCHELL, S. D.: Function, Fitness and Disposition. Biology and Philosophy, 10 (1995) 39-54.

[51] Quot. in METZ, S.: A Wake for Clausewitz: Toward a Philosophy of $21^{\text {st }}$ Century Warfare. Parameters, Winter (1994-95) 132. 